\section{ON AUSCULTATION OF THE GSOPHAGUS.*}

Br T. CLIFFORD AI.LBUTT, M.D., Physician to the General Infirmary, Leeds.

DisEASEs of the asophagus often prove somewhat diffeult of investigation, and it is not likely that we shail ever succecd in bringing this tube within the range of vision, as we have brought the larynx, the inner eye, and even the cavity of the bladder. Jisenses of the oesopha. gus, moreover, even when benignant in chr.racter, have a peculiar terror in the peril of starvation which threatens the sufferer. Any help, then, which we can obtain either i:t our clingnosis or our treatment of disease in this part, should be carefully cherished; and for this reason I venture to bring before you a means of diagnosis which, in my opinion, has been unduly neglected. The only means used in cases of alleged disease of the ocsophagus are the catechising of the patient and his friends, and the exploration of the tube with the sound; and not unfrequently this latter cannot safely or judiciously be employed; in which case we are wholly dependent upon more general clinical observation and inquiry. The method of auscultation of the a-sophagus which I have found to be useful is especially uscful in cases of this kind, and will tell us much that we could not otherwise discover with any certainty. Nevertheless, I do not find that auscultation of the osophagus is commonly practised. Nay, I cannot call to mind a single consultation in a case of this kind where the patient's medical attendant had used auscultation, or had even henrd of it before pointed it out to him. Nor, again, in the ordinary text-books on medicine do I find any allusion to auscultation of the cesophagus; nor is it described in special treatises on auscultation. So far as I know, the only systematic account of the methorl is to be found in the papers of Hamburger, which appeared in the Usterverichische Mrdicin. Fahr. biucher for 1867.8.9. My own initiation into the plan was through these papers; but whether IIamburger was the first to introduce it into practice, I know not, nor in this place does it much ma!ter. During the six or seven years that I have tested IIamburger's statements, have found that, although there is nuch exnggeration, inaccuracy and whim in his way of putting them, nevertheless, after all deductions, there remains a solid residue of valuable olsservation.

The method of auscultation of the osophagus depends upon the nudibility of the swallow both in the neck and thorax. It is best, of course, to educate the car at first upon a healthy subject. The subject is requested to take a mouthful of water, and to swallow it at a signal. The operator then places the stethoscope (Sibson's stethoscope is the best for the purpose, I find, but any ste: hoscope will do) first upon the trachea anywhere between the hyoid bone and the supraclavicular fossa. The signal being given, the patient now swallows; and, as he does so, a very distinct resonant gurgle is heard at the place of the stethoscope. This sound, which is very loud at the hyoid bone, where the water is as it were slung through a tube into the observer's ear, be. comes duller as the instrument is renoved to deeper parts of the neck. Below the cricoid cartilage, the sound is more heavy or solid in character, and the morsel is as it were shoved downwards with a whiz. To examine the lower part of the assophagus, the it:strument must be removed to the spine, and must be carried down the left side of the -spines of the first eight dorsal vertebrac. Here the sound is still more clistant, though still very distinct, and is like a smooth bocly slipping through with a sort of cluck.

By repeated observations upon the healthy subject, the operator must make himself thoroughly familiar with the tone, with the appa. rent size of the morsel, with the energy of the osophngtal contraction, with the rapidity of it, and also with the direction of the morsel. The rapidity of the passage of the morsel is ascertained by putting the instrument over the cardiac orifice while a finger is placed upon the larynx. The moment of commencement of deglutition is known pre. cisely by the rise of the larynx; the moment of its completion is recog. nised by the car. The rate of the swallow varies a little in individuals, and is generally distinctly slower in weakly persons at all times, and in healthy persons after a prolonged meal. The direction of the swallow may be reversed, as in regurgitation. In this case, the gulped fluid eddies as it were in a funnel with a prolonged resonant gurple; or the direction of the sivallow may be diverted, as in one case uncler my notice, where the cesophagus was perforated, and the matters escaped into the pleural cavity. Hamburger had more than one case of the kind; and he pre. pared me to recognise this condition, which was quite ensy when one was thus forewarned. The small quantity of cliverted fluid passed through the chink in the oesophagus with a kind of sizzing nurmur. Pyopneumo-

- Read before the Medical Section at the Annual Meeting of the British Medical thorax of course was present as a consequence, and there was thereby a metallic quality added to the tone. Or, again, while the swallow still runs in the tube, it may be heard to cross the vertebral column, and to appear on the right side only for a greater or less distance. Hamburger relates a case of this kind, in which it was found, after death, that the cesophagus had been pushed over by an aneurism of the descending aorta. The swallow was in no way interfered with, so that it seems desirable to auscultate the cesophagus as a routine in cases of sus. pected aneurism of the descending aorta. The energy of the swallow must be considered apart from its rapiclity. In cases of dilated osophagus, the fluid may pass the tube quickly enough; but the absence of energy of contraction is known by the want of grasp. The fluid passes dow'n the tube with a squirting or running sound, not as though slung in a piece. It must be remembered, however, that in obstruction at the cardiac orifice, the accumulation of mucus may, and often does, modify or prevent the usual sounds for some five or six inches above the seat of the disease. In tender places, as in ulcers of the osophagus, Ham. burger says that the morsel may seem to stick or recoil. My own experience does not enable me as yet to speak decidedly on this point. It sounds to me rather like an over-refinement. So, again, with the rubbing or friction-sounds in inflammation of the tube, which I certainly have never been able mysclf to detect. But the tone of the swallow, on the other hand, is changed in quality by the presence of rough ulcers and the like on the inner surface of the tube, so that it be. comes deadened; though the more common and more easily known result is the prolongation of the morsel. It is, indeed, the prolongntion of the morsel which, more than all other changes, has caught my own enr. Almost all changes in the inner surface of the tube may be regardecl as diminutions of its calibre, and ns checks to its peristalsis : so that, where discase exists, be it ulcer, be it contraction, be it cumour, we hear there a slackening of the rate at which the morsel is slung downwards, and a prolongation of the morsel itself. It tails off and slackens as it passes by. If the stricture be tighter, the morsel, when it reaches the spot, eddies through with a creak, or even with a squeak. If the stricture be tighter still, we hear the resonant regurgitation of which I have alreacly spoken.

After thus describing the changes in the swallow readily to be heard in the various states of cliscase, I need not stay to point out how valuable these signs must prove in the consulting-room. My hearers will be astonished, when tlacy put it to the test, how readily they will spot the exact site of an organic stricture, and how easily they may prove the nervous nature of a clysphagia which causes no stethoscopic disturbances in the swallow. Time will not allow me to read notes of the nuinerous cases in which I have found osophageal auscultation of value; but among the best of them are many in which the absence of organic stricture was thus almost proved, to the infinite satisfaction of timid patients and their timid friends, who shrank in fear from the name of the sound; while in others the unmistakable signs of a local stricture have forbidden us to nurse any hopes of a spasm which might pass away. For spasmodic dysphagia is unknown to the stethoscope.

\section{SYME'S OPERATION MODIFIED AND IMPROVED BY SAVING THE PERIOSTEUM OF THE OS CALCIS.}

\section{By J OSEPH B E L L, F.R.C.S.Ed.,} Surgeon to the Edinburgh Royal Infirmary.

Pirocoff's operation is by somc preferred to Syme's, as it leaves, or is said to leave, a more useful stump, while at the same time it avoids the difficult and tedious dissection of the soft parts from the os calcis.

A plan I have used for some three or four years, and practised in ten cases, will, I believe, be found to give the advantages promised by Pirogofi's method, and yet to avoid the risk of recurrence of disease of bone in the portion of os calcis left in Pirogoft's operation.

It is a very simple and slight modification, and consists in leaving attached to the flap the periosteum of the posterior part of the os calcis, and instead of dissecting the soft parts alone of the bone, stripping alnng with them the whole periosteum. In the case of am. putation for disease of tarsus in children, this is done with the most perfect ease. It adds to the chance of vitality of flaps, diminishes the risk of slonghing and number of vessels to tie, and gives the most excellent results. Especially if the patient be encouraged early to move his flap by means of the tendons which soon take on new adhe. sions, we find that a considerable power of moving the heel flap orer the end of tibia is saved, and, in some cases, denl of new bone is formed from the periosteum. So much so is this the case, that in 